\title{
From bright windows to dark spots: The evolution of melt pond optical properties during refreezing
}

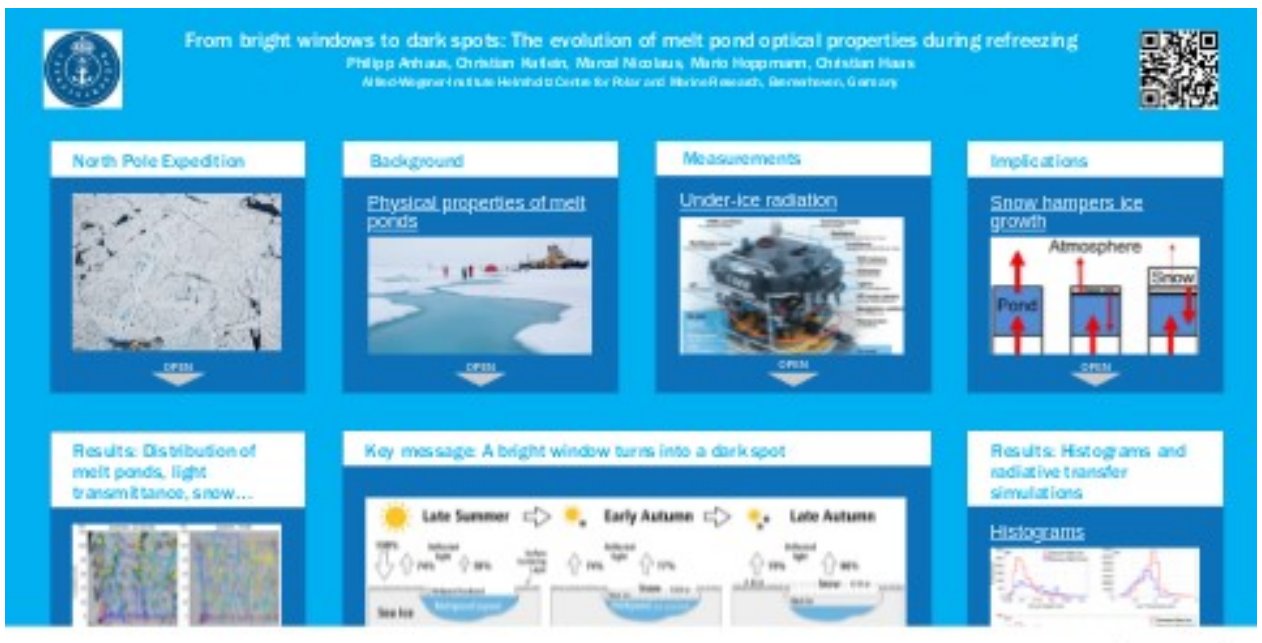

Philipp Anhaus, Christian Katlein, Marcel Nicolaus, Mario Hoppmann, Christian Haas Alfred-Wegener-Institute Helmholtz Centre for Polar and Marine Research, Bremerhaven, Germany
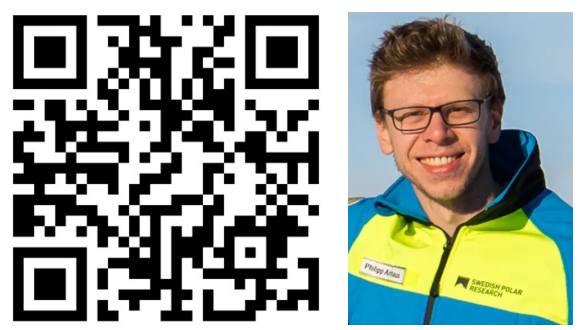

PRESENTED AT: 


\section{NORTH POLE EXPEDITION}

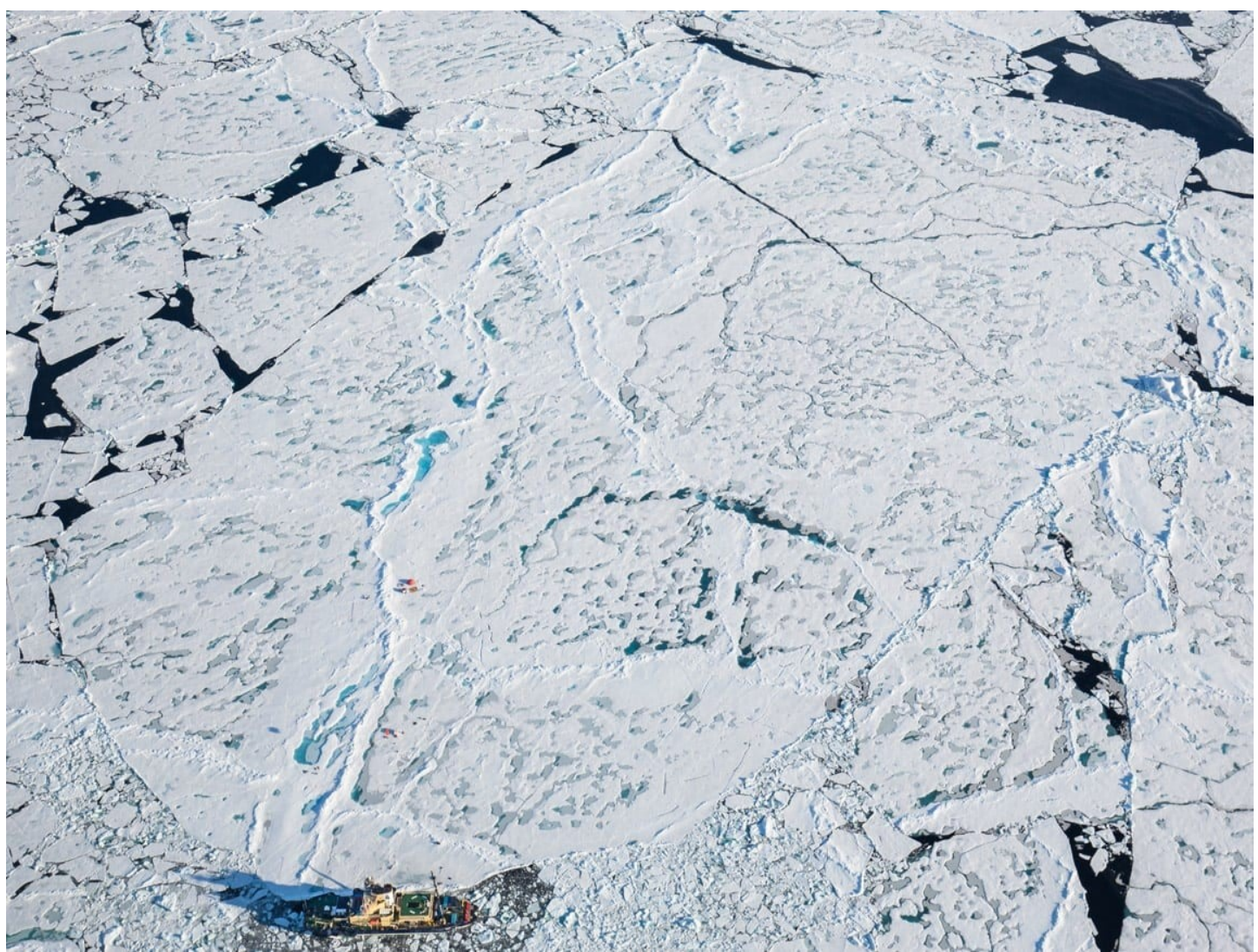

Figure: Aerial image taken during a low helicopter flgiht on 14 August 2018. Photo credit: Lars Lehnert, SPRS.

- Arctic Ocean 2018 MOCCHA - ACAS - ICE campaign (short: AO18) onboard the Swedish icebreaker Oden

- Temporary ice camp on drifting, ponded multi-year ice close to the geographic North Pole

- 14 August to 14 September 2018 


\section{BACKGROUND}

\section{Physical properties of melt ponds}

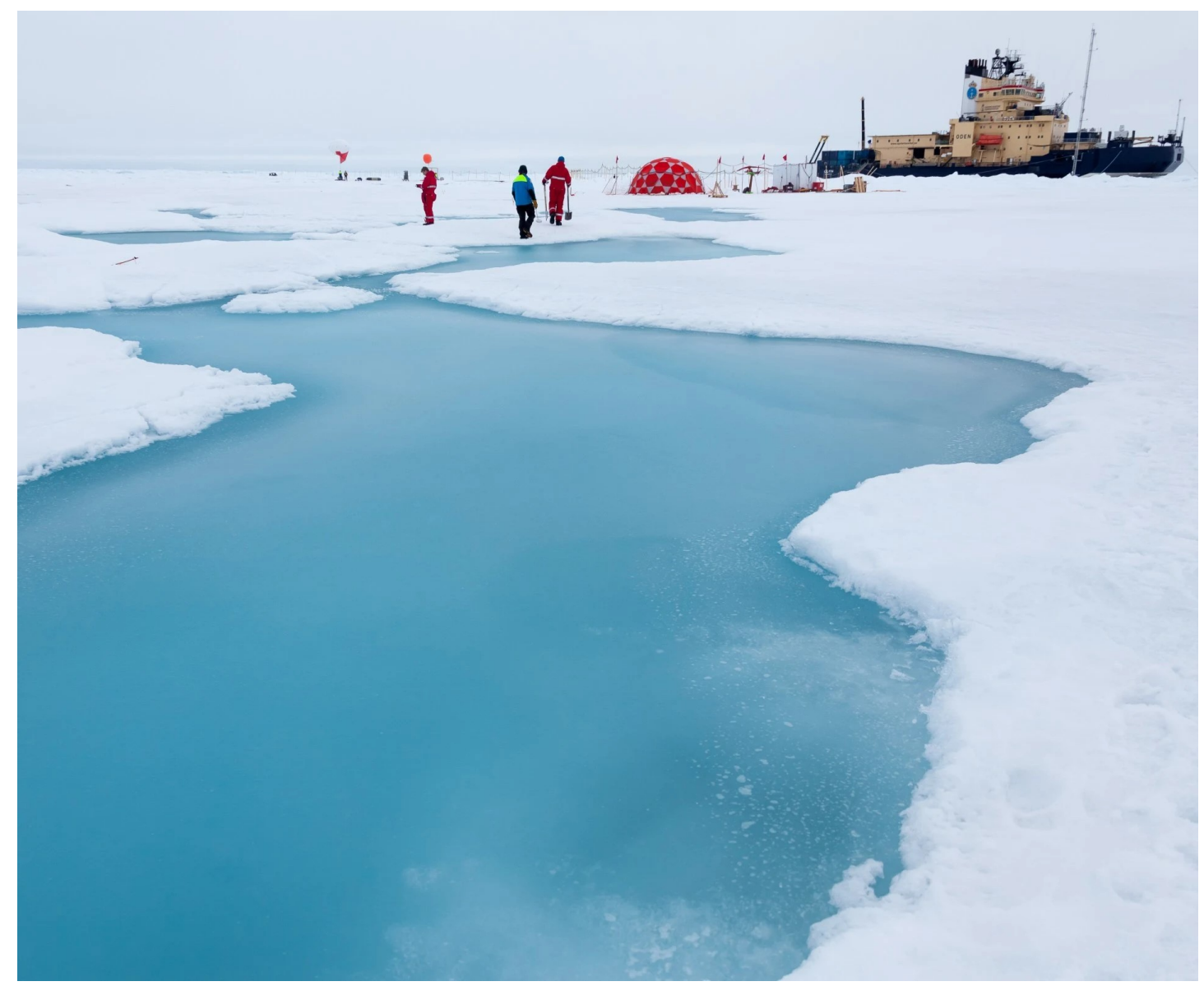

Figure: The surface of melt ponds is lower than that of adjacent bare ice.

- Melt ponds are topographic lows 


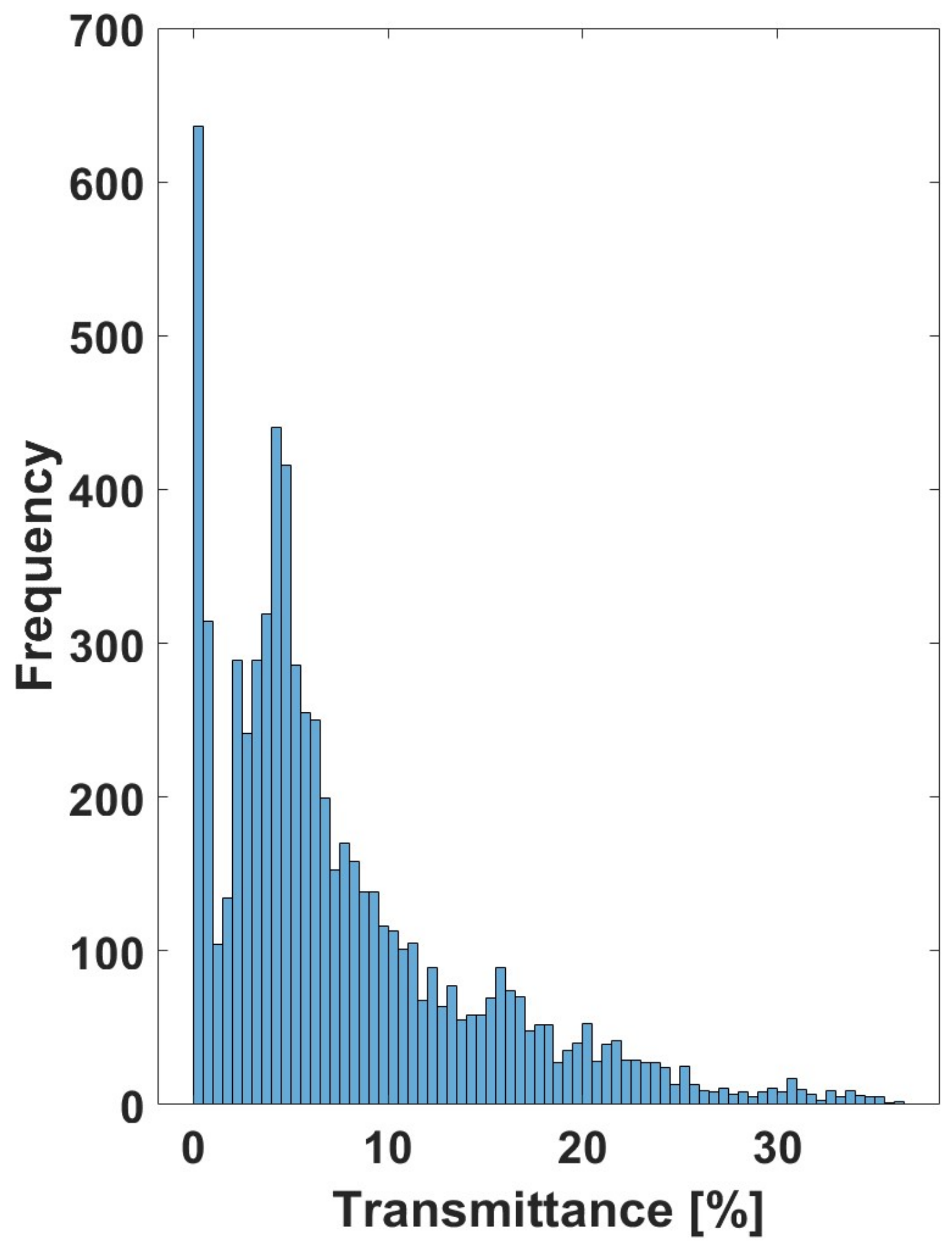

Figure: Histogram of light transmittance for typical Arctic summer sea ice.

- Bi-modal transmittance distribution on summer Arctic sea ice

- Mode of $0.5 \%$ is associated with bare ice and $4.5 \%$ with melt ponds 


\section{- Translucent melt ponds cause higher light transmittance}

- In the existing literature, it is documented that in the transition to autumn the transmittance of melt ponds and bare ice decreases equally, so that the transmittance of melt ponds remains always higher than that of bare ice (e.g., Katlein et al., 2019)

- This is why melt ponds are considered bright windows of Arctic sea ice, also during autumn

Ecological properties of melt ponds

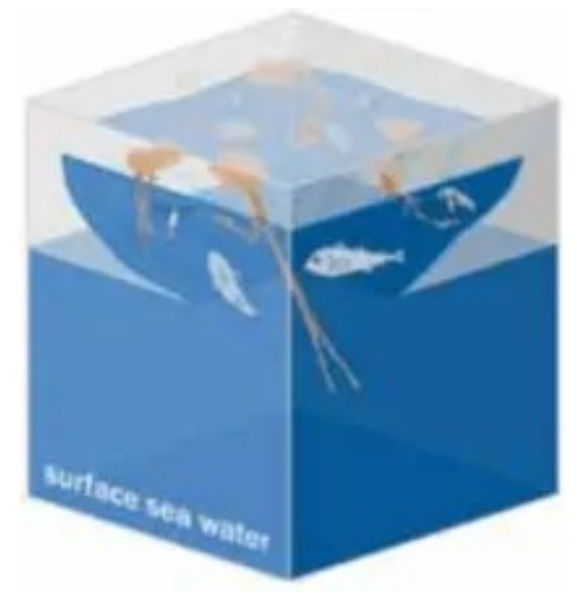

Figure: Biomass underneath open melt ponds (Lee et al., 2011).

- Biomass accumulates also under refrozen melt ponds in autumn due to more light (Lee et al., 2011). 


\section{MEASUREMENTS}

\section{$\underline{\text { Under-ice radiation }}$}

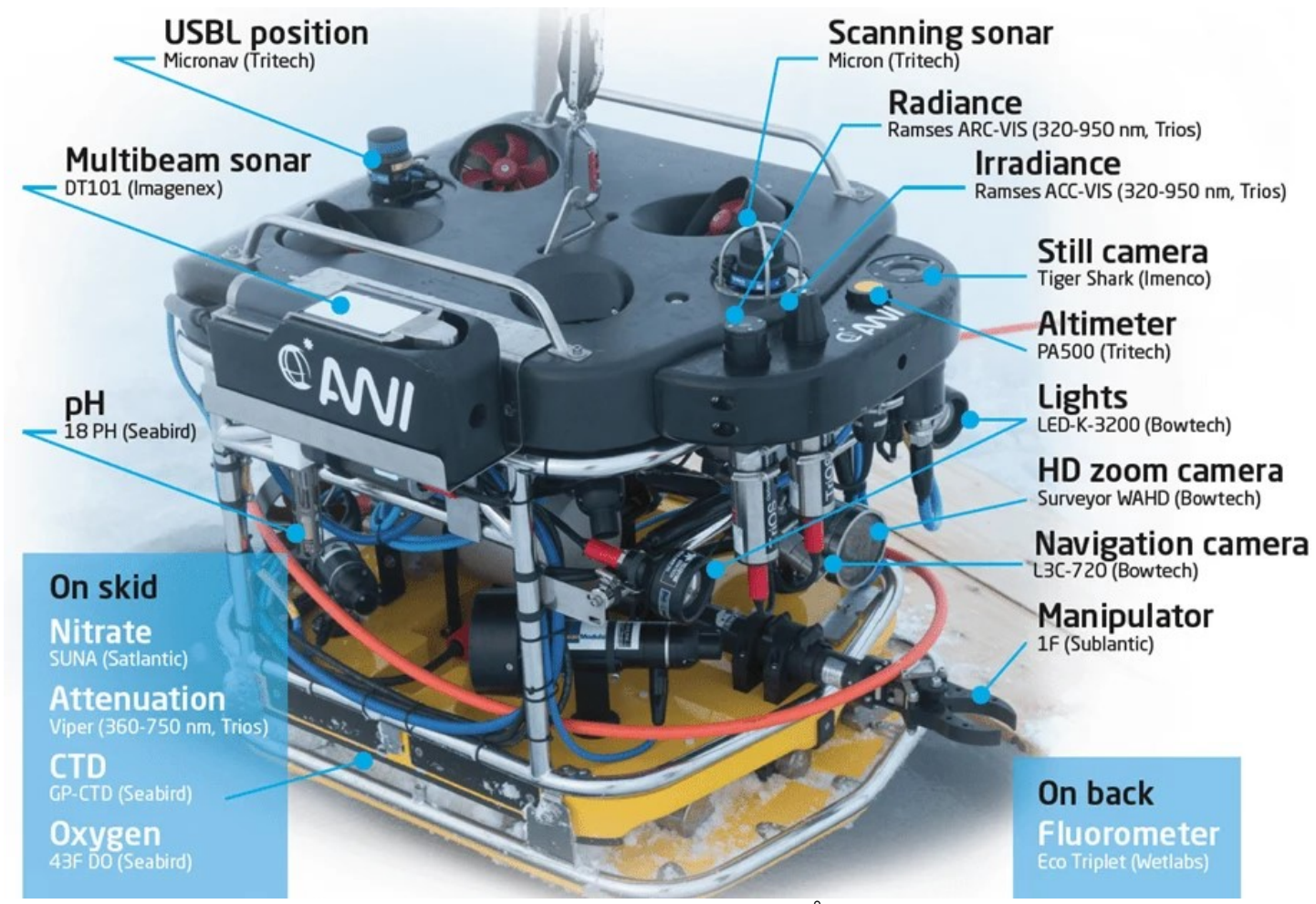

Figure: Remotely operated vehicle BEAST (Ocean Modules, Åtvidaberg, Sweden, Katlein et al., 2017).

- operated underneath the sea ice

- measures under-ice irradiance

- transmittance $=$ under-ice irradiance / surface irradiance

\section{Total ice thickness}




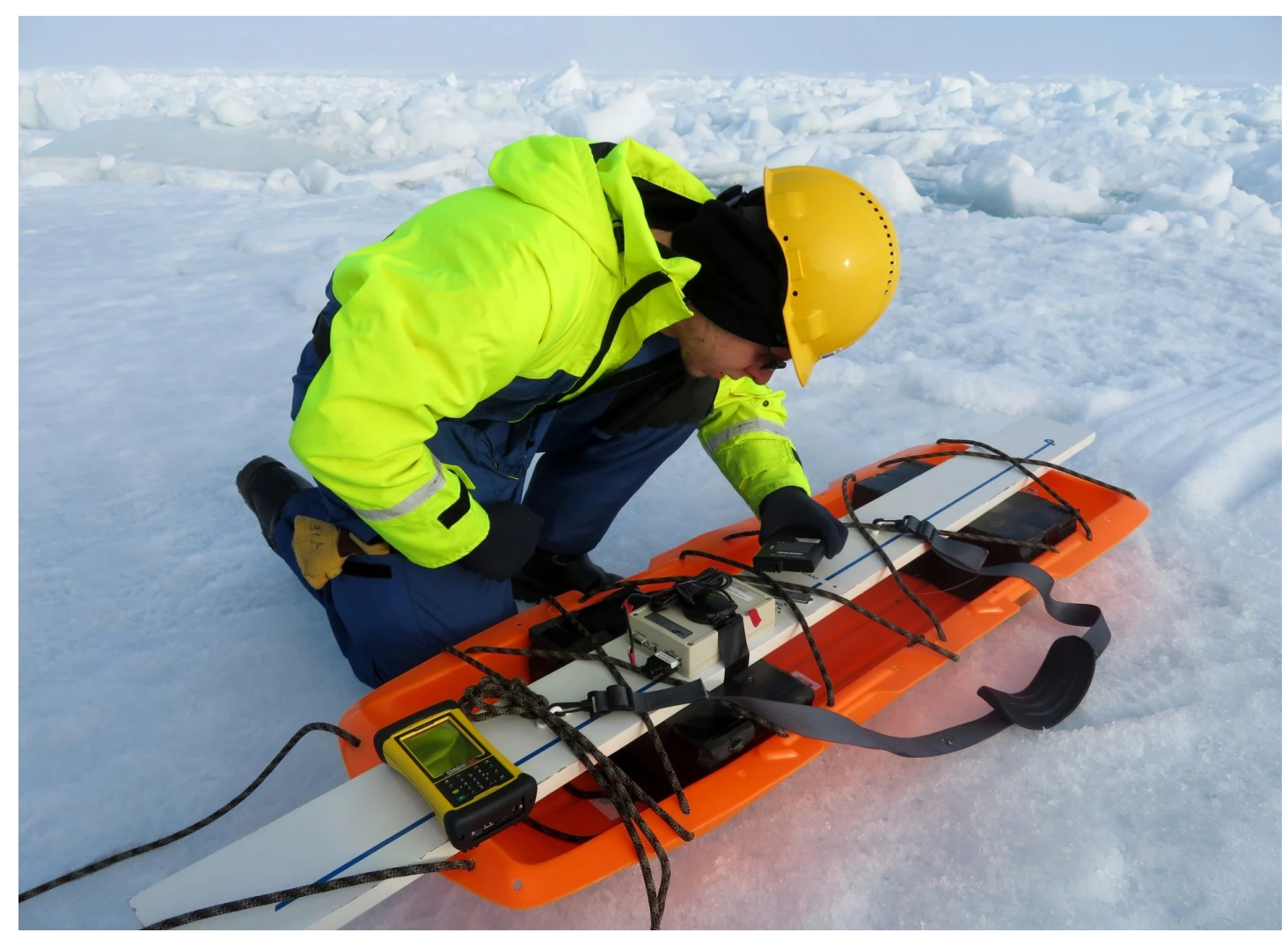

Figure: Ground-based electromagnetic induction sounding device (GEM-2, Geophex Ltd, Raleigh, NC, USA, Hunkeler, 2016; Hunkeler et al., 2016).

\section{Snow depth}




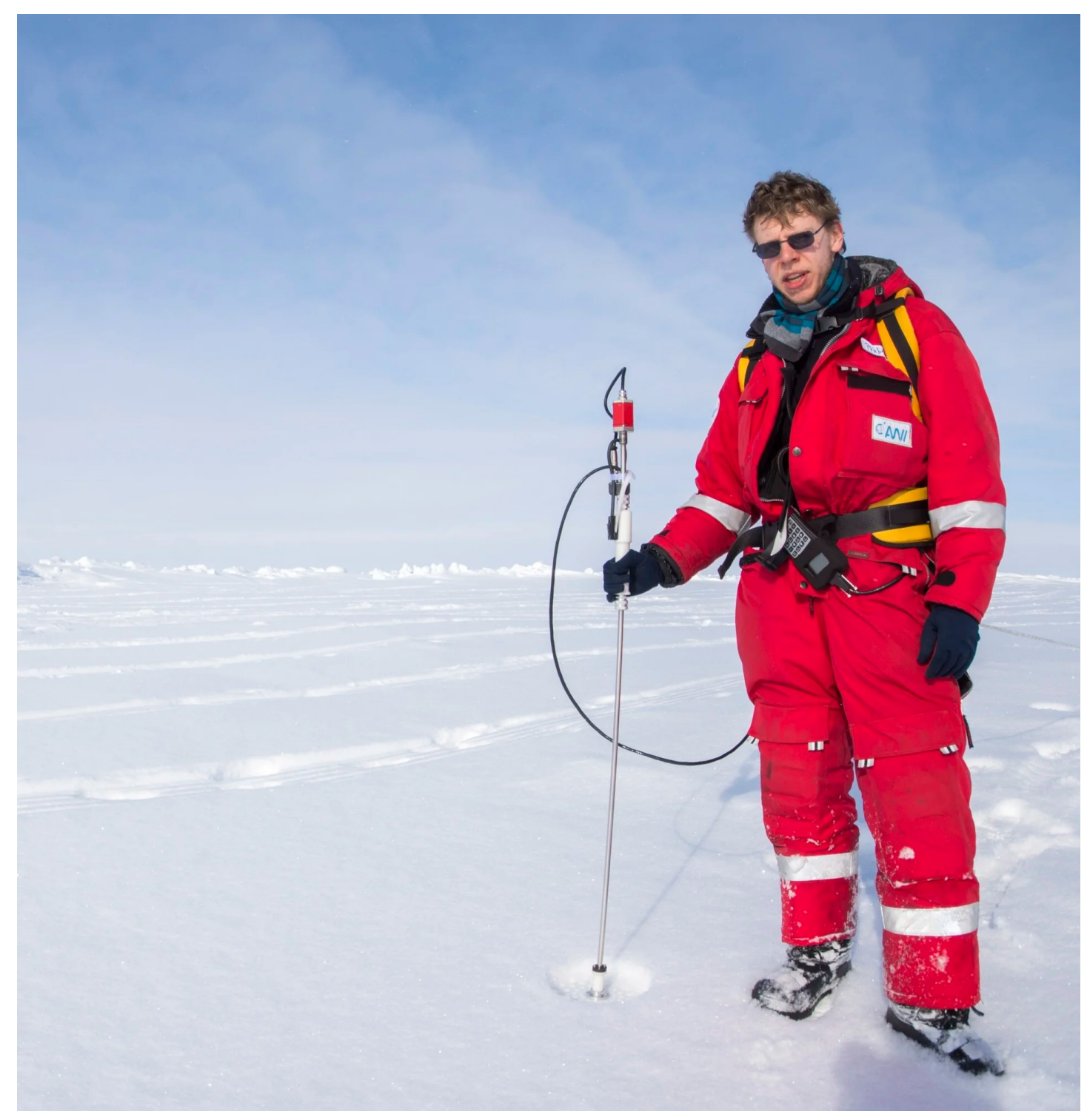

Figure: Magnaprobe (Snow-Hydro, Fairbanks, AK, USA, Sturm and Holmgren, 2018). Photo credit: Pierre Coupel, DFO 


\section{IMPLICATIONS}

Snow hampers ice growth

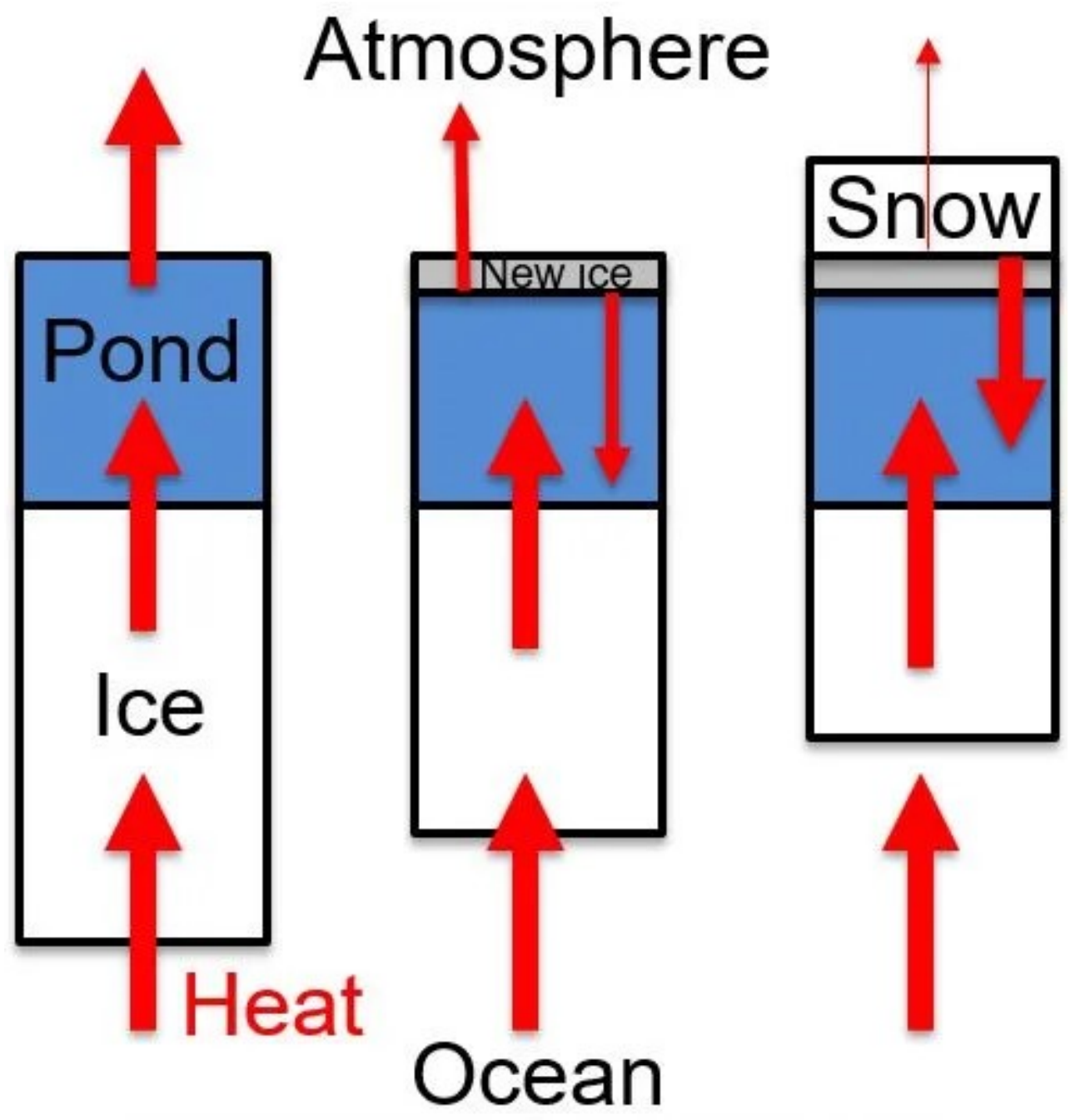

Figure: Schematic of heat transfer for ice-ocean-atmosphere system.

- Thinner ice more vulnerable to dynamic and warming events

- Induces rougher bottom topography, affects mass, momentum, heat, and salt fluxes

Biomass accumulates also under refrozen melt ponds in autumn due to more light -> food source (Lee et al., 2011) 


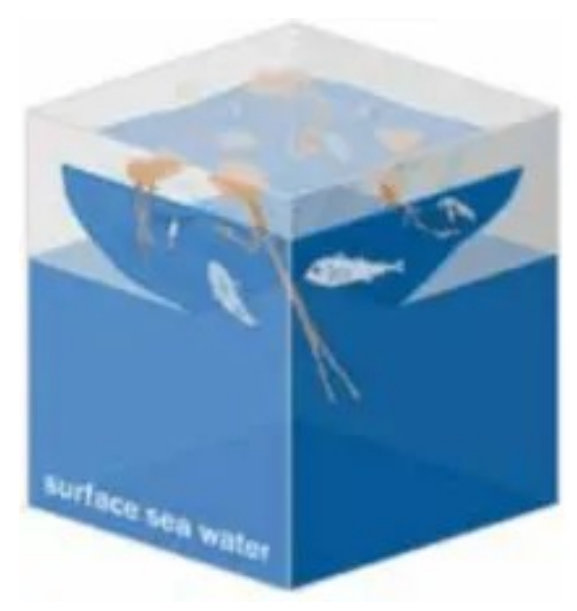

Figure: Biomass underneath open melt ponds (Lee et al., 2011).

However, snow decreases light under melt ponds

Effects on where, which, and how biomass is distributed udner sea ice 


\title{
RESULTS: DISTRIBUTION OF MELT PONDS, LIGHT TRANSMITTANCE, SNOW DEPTH, AND ICE THICKNESS
}
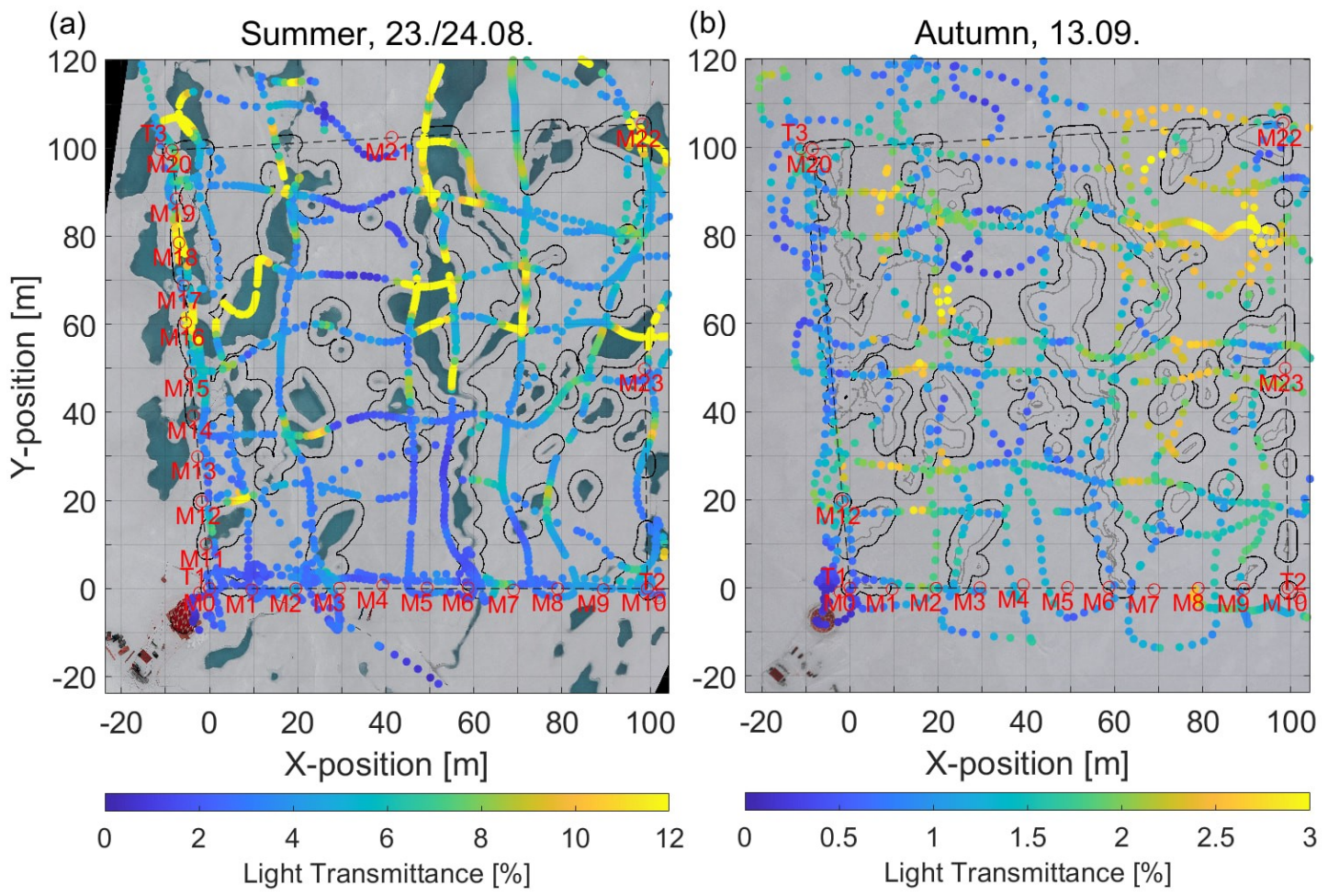

Figure: Distribution of melt ponds and bare ice on drifting MYI in the Central Arctic during the transition from (a) summer to (b) autumn. The surfaces of the melt ponds were partly open and partly refrozen in (a) and completely refrozen and snow-covered in (b). Overlaid is light transmittance as measured using an ROV. The background images are orthorectified aerial images acquired during (a) a low altitude helicopter flight and (b) a drone flight. Pixels within the study area that were classified as melt pond and used for further analysis are outlined by the melt ponds themselves in (a) and by the grey line in (b). The surfaces of the melt ponds in (b) were refrozen and snow-covered but marked blue for illustration purposes. The edges around the melt ponds in (a) and (b) were dilated by a buffer of about $2 \mathrm{~m}$ indicated by the black line. Red labels indicate the marker (M) and transponder locations (T). The ROV tent and control hut are visible on the lower left corners of the images. Note the different range in transmittance in (a) and (b). Photo credit for (b): Lars Lehnert, SPRS.

\section{- (a) Summer: Transmittance below melt ponds higher than below bare ice}

\author{
- (b) Autumn: Transmittance below melt ponds lower \\ than below bare ice
}



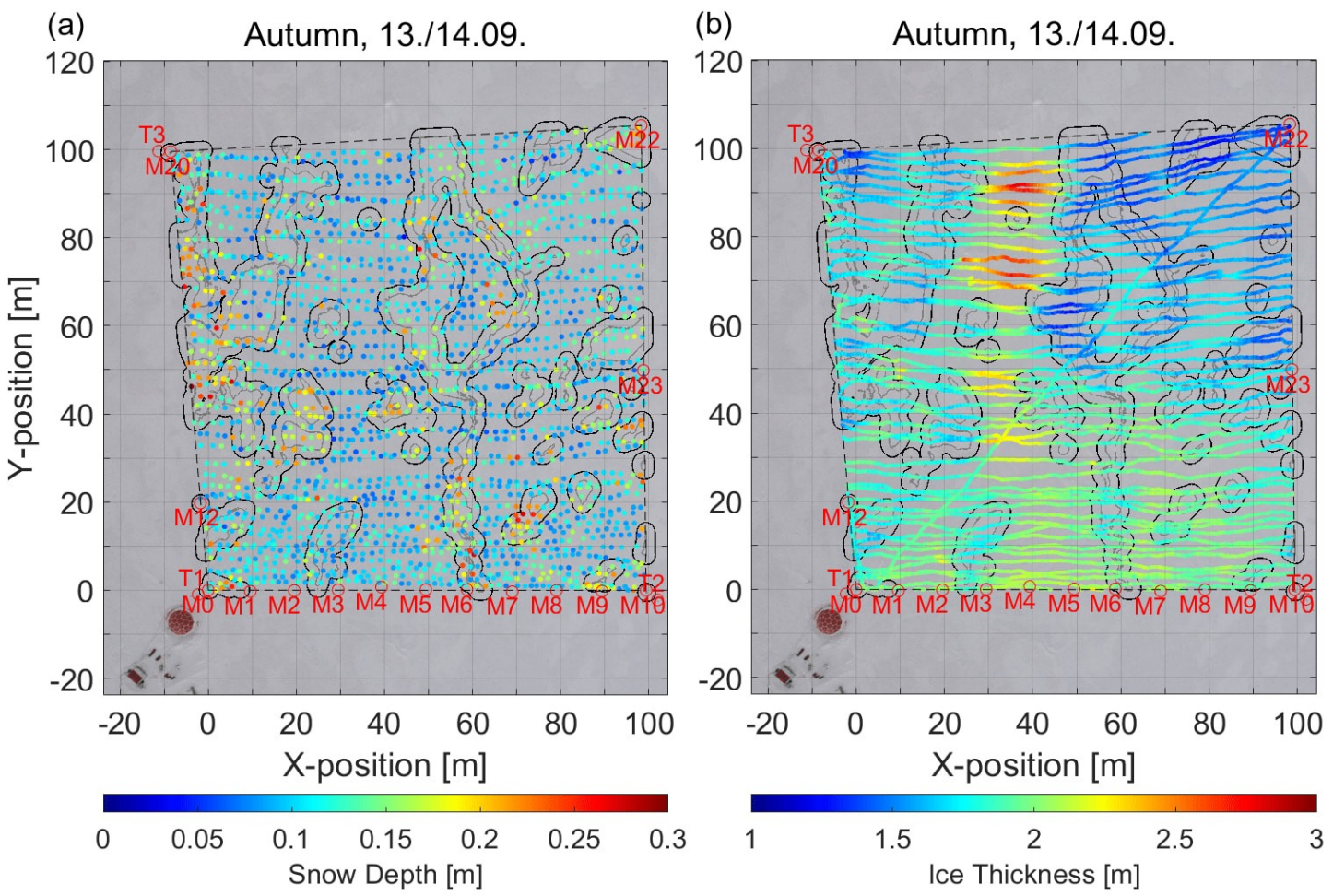

Figure: (a) Snow depth and (b) ice thickness on ponded sea ice as measured on 14 September (autumn). The background images are orthorectified aerial images acquired during a drone flight on 13 September. Pixels within the area of focus that were classified as melt pond during the summer are outlined by the grey lines to illustrate the refrozen and snow-covered ponds during autumn. The edges around the melt ponds were dilated by a buffer of about $2 \mathrm{~m}$ indicated by the black lines. This area is indicated by a brighter blue. Red labels indicate the marker (M) and transponder locations (T). The ROV tent and control hut are visible on the lower left corners of the images. Photo credit: Lars Lehnert, SPRS. 


\section{KEY MESSAGE: A BRIGHT WINDOW TURNS INTO A DARK SPOT}

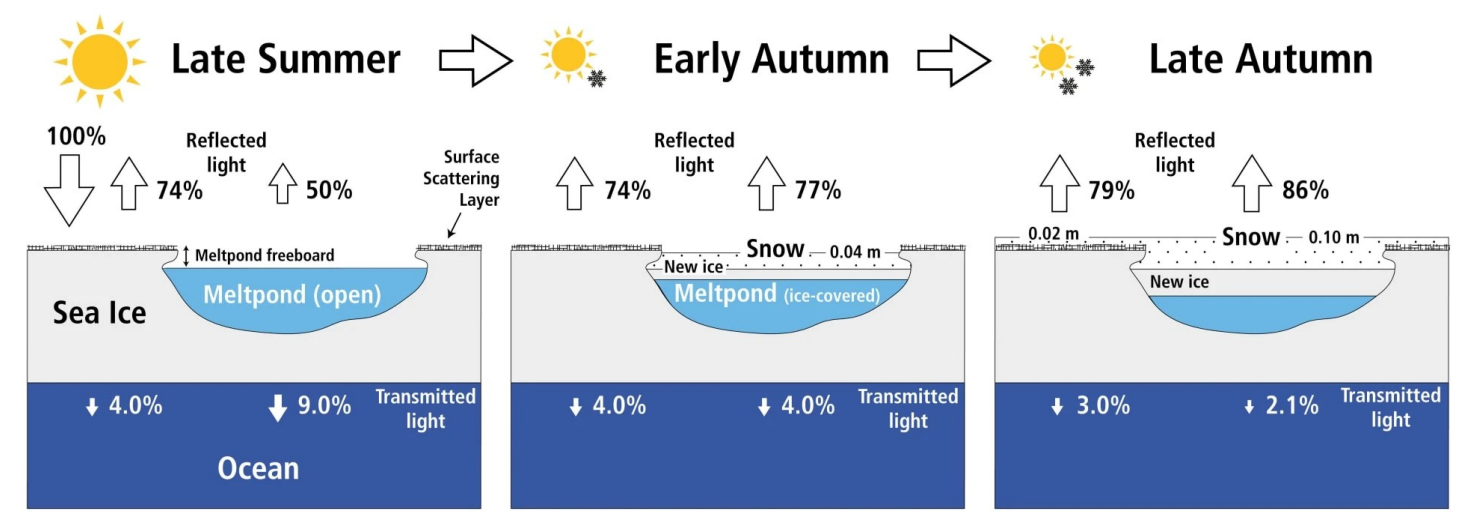

Figure: During the transition from summer to autumn, snow predominantly accumulated on the recessed surface of frozen melt ponds, resulting in a reversal of the light transmittance between melt ponds and bare ice. Numbers result from the radiative transfer model DORT2002.

\section{- Snow mainly accumulated on recessed surface of frozen melt ponds}

\section{- Reversal of light transmittance between melt ponds} and bare ice 


\section{RESULTS: HISTOGRAMS AND RADIATIVE TRANSFER SIMULATIONS}

\section{$\underline{\text { Histograms }}$}
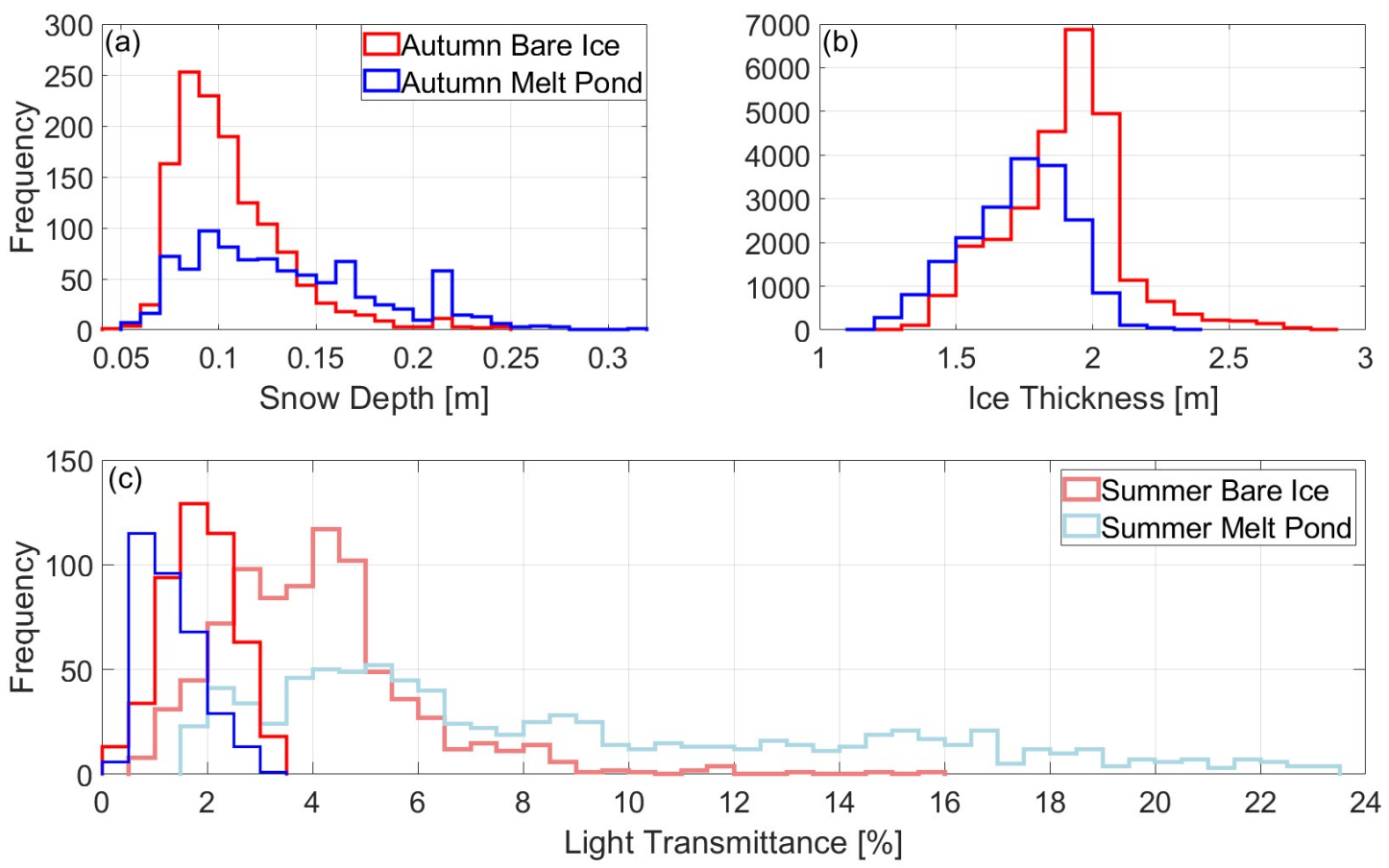

Figure: Histograms of measured (a) snow depth, (b) ice thickness, and (c) light transmittance of melt ponds and bare ice.

- (a) Thicker snow cover on melt ponds than on bare ice

- (c) Summer: Transmittance of melt ponds higher than that of bare ice

- (c) Autumn: Transmittance of melt ponds lower than that of bare ice

$\underline{\text { Radiative transfer model }}$ 


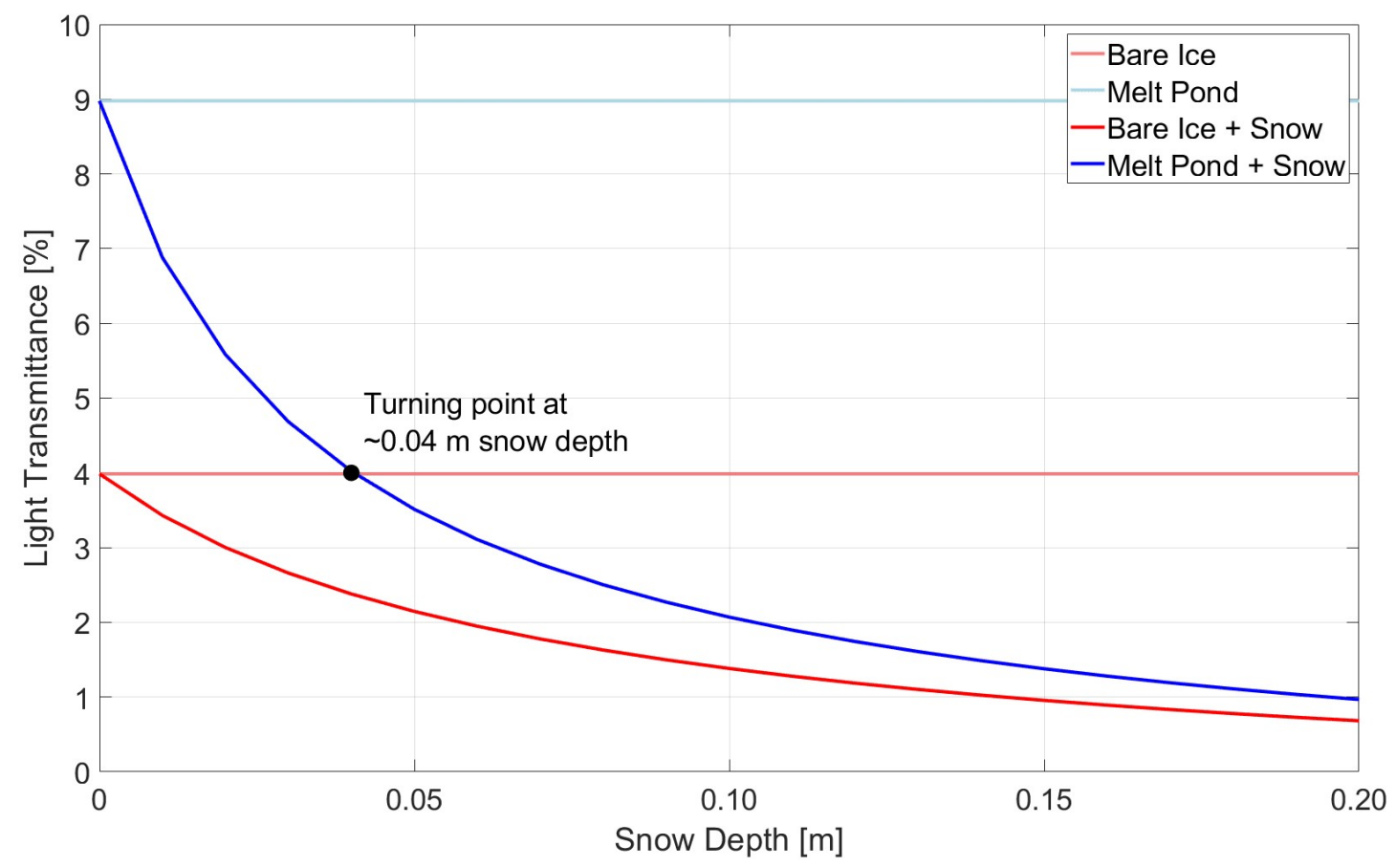

Figure: Light transmittance simulations using the radiative transfer model DORT2002 (Edström, 2005).

- Transmittance below melt ponds become lower than that below bare ice for a snow depth of $0.04 \mathrm{~m}$ 


\section{AUTHOR INFORMATION}

Philipp Anhaus ${ }^{1}$, Christian Katlein ${ }^{1}$, Marcel Nicolaus ${ }^{1}$, Mario Hoppmann ${ }^{1}$, Christian Haas ${ }^{1}$

${ }^{1}$ Alfred-Wegener-Institut Helmholtz-Zentrum für Polar- und Meeresforschung, Bremerhaven, Germany 


\section{ABSTRACT}

Melt ponds have a strong impact on the Arctic surface energy balance and the ice-associated ecosystem because they transmit more solar radiation compared to bare ice. In the existing literature, melt ponds are considered as bright windows to the ocean, even during freeze-up in autumn. In the central Arctic during the summer-autumn transition in 2018, we encountered a situation where more snow accumulated on refrozen melt ponds compared to the adjacent bare ice, leading to a reduction in light transmittance of the ponds even below that of bare ice. Results from a radiative transfer model support this finding. This situation has not been described in the literature before, but has potentially strong implications for example, on autumn ecosystem activity, oceanic heat budget and thermodynamic ice growth. 


\section{REFERENCES}

This poster: Anhaus, P., Katlein, C., Nicolaus, M., Hoppmann, M., \& Haas, C. (2021). From bright windows to dark spots: Snow cover controls melt pond optical properties during refreezing. Geophysical Research Letters, 48, doi:10.1029/2021GL095369

Edström, P. (2005). A Fast and Stable Solution Method for the Radiative Transfer Problem. Society for Industrial and Applied Mathematics Review., 47(3). doi:10.1137/s0036144503438718

Hunkeler, P. A. (2016). Sea-ice thickness and porosity from multi-frequency electromagnetic induction sounding: Application to the sub-ice platelet layer in Atka Bay, Antarctica, PhD thesis, Jacobs University Bremen. hdl:10013/epic.47466

Hunkeler, P. A., Hoppmann, M., Hendricks, S., Kalscheuer, T., and Gerdes, R. (2016). A glimpse beneath Antarctic sea ice: Platelet layer volume from multifrequency electromagnetic induction sounding. Geophysical Research Letters, 43(1). doi:10.1002/2015g1065074

Katlein, C., Schiller, M., Belter, H. J., Coppolaro, V., Wenslandt, D., and Nicolaus, M. (2017). A New Remotely Operated Sensor Platform for Interdisciplinary Observations under Sea Ice. Frontiers in Marine Science, 4, doi: $10.3389 /$ fmars.2017.00281

Katlein, C., Arndt, S., Belter, H. J., Castellani, G., and Nicolaus, M. (2019). Seasonal Evolution of Light Transmission Distributions Through Arctic Sea Ice. Journal of Geophysical Research: Oceans, 124(8). doi:10.1029/2018jc014833

Lee, S. H., McRoy, C. P., Joo, H. M., Gradinger, R., Cui, H., Yun, M. S., et al. (2011). Holes in Progressively Thinning Arctic Sea Ice Lead to New Ice Algae Habitat. Oceanography, 24(3). doi:10.5670/oceanog.2011.81

Sturm, M., and Holmgren, J. (2018). An Automatic Snow Depth Probe for Field Validation Campaigns. Water Resources Research, 54(11). doi:10.1029/2018wr023559 